\title{
Analysis on the Mechanism of Digital Economy Boosting the High-quality Development of Agriculture in China
}

\author{
Jianhua Zhao ${ }^{1, a^{*}}$, Yanyu Gong ${ }^{1, b}$ \\ ${ }^{1}$ College of Management, Sichuan Agricultural University, Chengdu, China
}

\begin{abstract}
With the introduction and application of 5G, the digital economy has become a new driving force for the high-quality development of agriculture. This study takes the digital economy as the development-oriented 'digital village' Hebi City as a case, and analyzes the practical basis for the digital economy to promote the high-quality development of agriculture in China from three aspects: power change, quality change and efficiency change. This paper explains the theoretical mechanism of digital economy to promote the high-quality development of agriculture from four perspectives of infrastructure, technological innovation, talent training and industrial development, and strives to realize the three major changes in agriculture through digital economy, accelerates the digital transformation and upgrading of agriculture in China, and promotes the high-quality development of agriculture.
\end{abstract}

\section{INTRODUCTION}

The main contradiction in China's society has been transformed into a contradiction between the people's growing need for a better life and unbalanced and inadequate development. As far as the agricultural sector is concerned, the requirements for agricultural development have also shifted from the 'increasing production' stage of solving food and clothing to the 'increasing quality' stage of allowing people to eat nutritiously and healthy. In the Third Plenary Session of the 14th Central Committee, General Secretary Xi Jinping clearly pointed out that promoting the high-quality development of agriculture is the foundation of economic. The high-quality development of agriculture is the efficient use of resources at the agricultural production end, and the highly optimized agricultural industry structure, agricultural product output, and agricultural product quality under technology sharing innovation ${ }^{[1]}$. From the perspective of development practice, the main characteristics of the high-quality development of agriculture are green, high-quality, large-scale, and diversified development ${ }^{[2]}$. With the rapid development of new technologies such as the Internet, big data, and 5G, the digital economy has become a key driving force for economic growth. The high-quality development of agriculture in China meets the era of digital economy unexpectedly.

The digital economy is a new economic form that has emerged with the development of the information technology revolution $^{[3]}$. In 1996, Don Tapscott, the father of the digital economy, described the digital economy as an economy that 'using bits instead of atoms', which aroused extensive attention from scholars at home and abroad. For a long time, many foreign scholars have conducted useful theoretical explorations on the application of big data in specific industries, but most of them have focused on neuroscience ${ }^{[4]}$ and medical applications ${ }^{[5]}$. In recent years, the digital economy has been widely used in agricultural production practices. According to the evolution and characteristics of the digital economy, some domestic scholars have constructed a theoretical analysis framework of the rural information poverty alleviation ecosystem ${ }^{[6]}$, and some scholars have compared and reviewed 12 international and domestic digital economy-related indicator systems, and believed that the quality, sources of data are the key to the measurement of digital economy ${ }^{[7]}$, and some scholars have studied the impact of digital economy on the integrated development of rural primary, secondary and tertiary industries and agricultural modernization ${ }^{[8]}$. In general, the digital economy has brought new opportunities for new agricultural industry development model and organizational reshaping in China. The key to quality change, efficiency change and power change is 'digital economy empowerment'. However, how does the digital economy flooding agricultural production and life affect the high-quality development of agriculture in China? What is its practical basis and theoretical mechanism? How to seize the opportunities of the digital economy development, so that agriculture can increase benefits in improving quality and achieve higher-quality development? This is the question that needs to be studied urgently and also the significance of this study. 


\section{THE PRACTICAL BASIS OF DIGITAL ECONOMY BOOSTING THE HIGH-QUALITY DEVELOPMENT OF AGRICULTURE IN CHINA}

The 'White Paper on China's Digital Economy Development and Employment (2019)' shows: China's digital economy totaled 31.3 trillion RMB in 2018, accounting for $34.8 \%$ of GDP, and its contribution to GDP growth reached $67.9 \%$; in the same period, agricultural digital economy accounted for $7.3 \%$ of the increase in the industry, an increase of $0.8 \%$ compared to 2017. With the convergence and integration of 5G, Internet of Things, other information technologies and agriculture, the digital economy has become a core element in changing the mode of economic growth ${ }^{[9]}$, adding production 'data' productivity to high-quality ecological agriculture and organic agriculture ${ }^{[10]}$. Although there are regional differences in resource endowments, economic conditions, and technological levels in China's agricultural development, the overall development logic is clear: high-quality development of agriculture must achieve quality change, efficiency change, and power change. As a pioneer of agricultural digital economy in China, Hebi City has won the title of 'Advanced County in the Evaluation of the National County Digital Agriculture and Rural Development Level in 2018'. Therefore, from the perspective of 'three major changes in agriculture' and combined with the actual status quo of Hebi City, this study studies the practical basis for digital economy to promote high-quality development of agriculture.

\subsection{Strengthen the construction of agricultural digital infrastructure to create a good environment for the high-quality development of agricultural}

The digital economy promotes quality change for the high-quality development of agriculture. Hebi City uses mobile Internet and other technical means to build a network platform that combines online and offline, such as JD's self-operated and 'JD·Hebi Premium' special product hall, which provide farmers with scientific, accurate and timely information services in agricultural production, agricultural technology promotion, and agricultural materials trading, etc. 794 agro-information agencies have been built, and an integrated production and operation service system of 'information acquisition + agricultural product trading + agricultural information consultation + remote diagnosis + basic services + logistics and distribution' has been formed, which is the first to open up the 'last mile' of convenient services. The digital foundation of Hebi City has created a good business environment for its high-quality development of agriculture. Production according to market demand effectively reduces inventory backlog, and ultimately promotes the city's agriculture from blind production to precise production on demand, improving the quality of agricultural supply while optimizing the supply structure, which made agricultural supply consistent with market demand.
2.2 Strengthen the deep integration of the agricultural digital industry and breakthroughs in agricultural digital technology, and break the digital barriers for the high-quality development of agriculture

The digital economy promotes efficiency change for the high-quality development of agriculture. In recent years, Hebi City has established Hebi City's '5G' Industrial Park, JD Digital Economy Industrial Park and other digital industrial parks and bases, which have promoted the innovative application of agricultural and rural digital industries and provided strong support for the prosperity of the industry. At the same time, it pays attention to the construction of high-standard farmland, using of modern information technology applications efficiently such as satellite and land dual-base remote sensing farmland information collaborative inversion technology, to collect environmental elements, agronomic parameters etc. automatically, transmit them in real time, analyze intelligently, and publish in time, which promote the development of agricultural green ecology. In 2019, the average yield of wheat and corn per mu in Hebi City increased by $36 \mathrm{~kg}$ and $71 \mathrm{~kg}$ respectively, and the utilization rate of chemical fertilizers and pesticides increased by $6 \%$. The cost of labor, fertilizer, irrigation etc. was saved by 133 RMB per mu each year, and the added benefit was 359 RMB. While achieving highquality development of agriculture, it has promoted the increase in grain and oil production, agricultural efficiency and farmers' income.

\subsection{Cultivate agricultural digital talents and provide endogenous driving forces for the high- quality development of agriculture}

The digital economy promotes the power change for the high-quality development of agriculture. Hebi City accelerates the establishment of the 'Internet + Modern Agriculture' platform in Hebi's agricultural silicon valley, providing application services such as data collection, statistical analysis, and technical guidance for agricultural production and rural management. At the same time, it pays attention to the combination of 'production, study and research', relying on the agricultural silicon valley 'Rural Revitalization College' to mobilize the driving force of scientific and technological innovation and increase the conversion and application rate of agricultural technology. In the first half of 2019, Hebi City launched 6 training sessions for information personnel, with approximately 580 people participating, expanded the main body of agricultural big data of highquality, and became the driving force for the high-quality development of agriculture. Eventually, Hebi City became the first in Henan Province's agricultural and rural modernization in 2019. The development of the digital economy is inseparable from the cultivation of digital talents and the innovation of digital technology. 


\section{THE THEORETICAL MECHANISM OF DIGITAL ECONOMY BOOSTING THE HIGH-QUALITY DEVELOPMENT OF AGRICULTURE IN CHINA}

At this stage, the high-quality development of agriculture in China needs to realize agricultural quality change, efficiency change and power change. The digital economy provides a new mechanism for the realization of agricultural quality change, agricultural efficiency change and agricultural power change from the levels of digital foundation, digital technology, digital talents, and digital industry. Taking 'digital foundation -- digital technology - digital talents -- digital industry' as the analytical framework, this study constructs a theoretical mechanism for digital economy to promote the high-quality development of agriculture (see Figure 1).

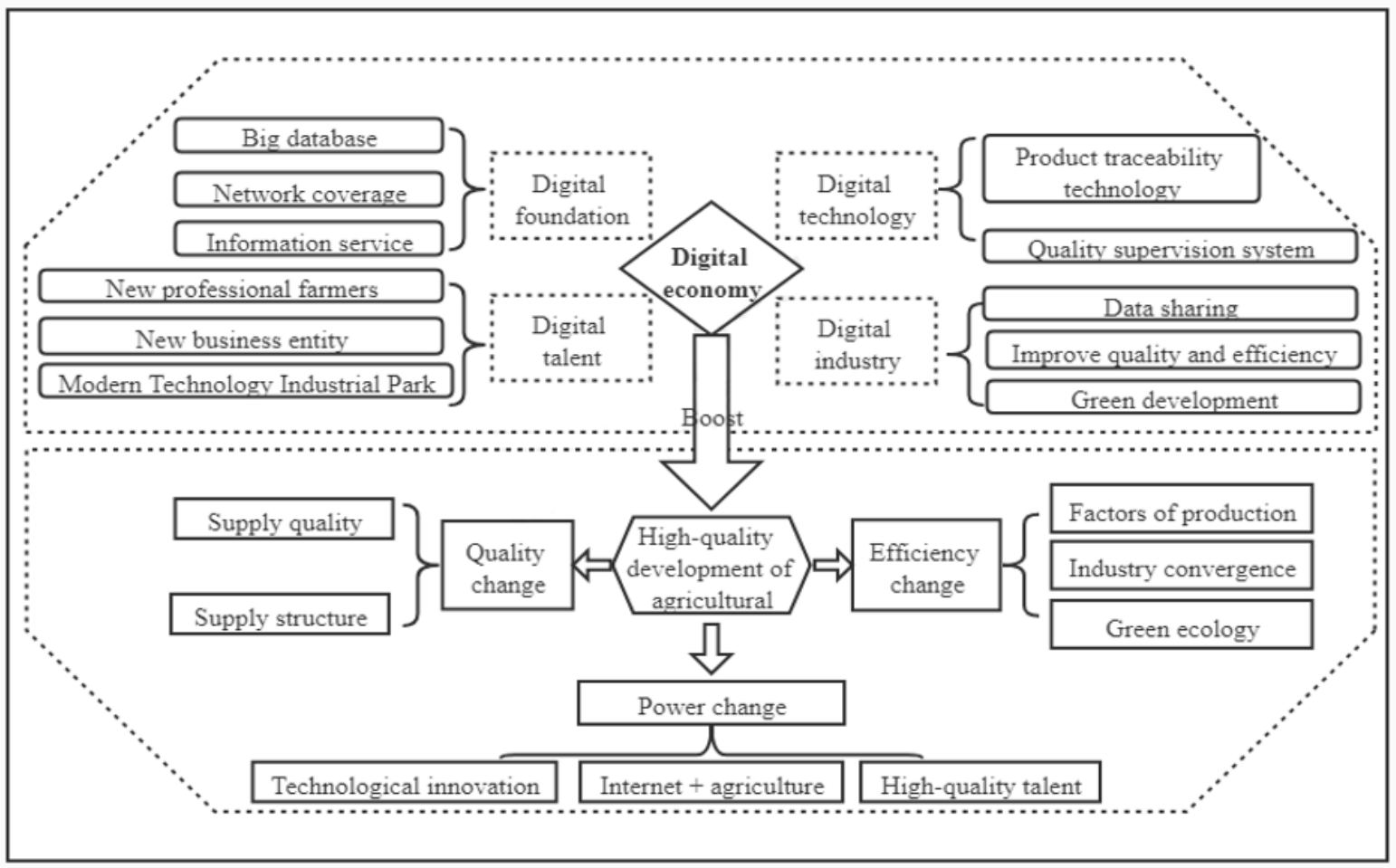

Figure.1 The theoretical mechanism of digital economy boosting the high-quality development of agriculture in China..

\subsection{The digital economy promotes the high- quality development of agriculture by improving efficiency at the level of digital basic}

The digital foundation contains a large number of information systems and undertakes functions such as data acquisition, storage, and sharing. Through the big data information in agricultural market, market demand can be more accurately understood, which is mainly reflected in two aspects: product supply and demand correlation and industry supply and demand correlation. Mismatch of supply and demand, overcapacity and lowend lock-in of the industrial structure have seriously hindered the high-quality development ${ }^{[11]}$, especially in remote rural areas in China, where farmers blindly follow the crowd and produce a certain crop without clear market demand, resulting in oversupply and overcapacity. Based on the large database in the digital foundation, farmers can query some market information through the Internet, and the government can also propose macro policies that are conducive to the effective allocation of resources based on data analysis, thereby improving the quality of agricultural supply in China.
3.2 The digital economy promotes the highquality development of agriculture through the realization of agricultural business model innovation at the level of digital technology

Digital technology refers to the use of modern computer technology to convert the traditional forms of various information resources into binary coded numbers that can be recognized by computer ${ }^{[12]}$. With the development of the digital economy, it has gradually evolved and promoted. As the key direction of the new round of technological revolution and industrial transformation, the cross-integration and in-depth integration of digital technologies have become more obvious, and the boundaries of the primary, secondary and tertiary industries have gradually disappeared. For example, the prediction and prevention of agricultural pests and diseases by remote sensing technology can be shared by both poor mountainous areas and first-tier cities. The output of digital technology is shared and open, which promotes the green and coordinated development of agriculture in China. Digital technology can organize production, management, sales, logistics and other 
business activities more accurately, and promote the highquality development of agriculture.

\subsection{The digital economy promotes the high- quality development of agriculture by liberating endogenous power at the level of digital talents}

Digital talents refer to talents with information, communication technology (ICT) professional skills and supplementary skills. The current shortage of digital talents in China has led to the lack of innovation in our country's agriculture in the digital economy. As talents are the main productivity, wherever there are talents, they can save agricultural production resources, protect the environment, and promote the green development of agriculture. A balanced and reasonable distribution of digital talents is conducive to promoting the modernization of agriculture and promoting the coordinated development of urban and rural areas in China. Therefore, the output of digital talents must be open and shared. At the same time, digital talents must be good at carrying out agricultural technological innovation and sharing knowledge actively, so that more people can become digital talents and liberate the endogenous power for high-quality development of agriculture.

\subsection{The digital economy promotes the high- quality development of agriculture by promoting industrial integration at the level of digital industry}

The digital industry is highly dependent on the channel capacity of network infrastructure. Therefore, the digital industry attaches importance to top-level design and the coordinated development of innovative elements, and it encourages regional innovation based on the resource endowments conditions and industrial development orientations of different regions. The digital industry optimizes the agricultural supply system, through intensification, standardization and branding to achieve lower cost, higher output and high quality of agricultural products. In the agricultural digital industrial park, the use of big data can accurately analyze the market demand and supply of products, improve the efficiency of agricultural production decision-making, and realize smart agriculture and digital agriculture. Therefore, the digital industry is based on the concept of data sharing and openness, promoting the coordinated development of agricultural input and output, and promoting the greening of the digital industry.

\section{REFERENCES}

1. Jiafei Wu. Research on the Framework and Countermeasures of Taiyuan's agricultural highquality development. Productivity Research, vol. 324, pp. 44-52.

2. Ling Xin, Xiaoning An. Construction and measurement analysis of our country's agricultural high-quality development evaluation system. Economic Review, vol. 402, pp. 115-124.

3. Xiao Si, Zhaoli Meng, Hualei Wang, et al. Digital economy: connotation, development and challenges. Internet World, 2017.

4. T J. Sejnowski, P S. Churchland, A. Movshonij. Putting big data to good use in neuroscience. Nature Neuroscience, vol. 17, pp. 1440-1441, 2014.

5. H M. Krumholz. Big data and new knowledge in medicine: the thinking, training, and tools needed for a learning health system. Health Affairs,vol. 33, pp. 1163-1170, 2014.

6. Lijuan Si. Construction and path optimization of rural information poverty alleviation ecosystem in the digital economy era. Books \& Information, vol. 000(002), pp. 37-45, 2019.

7. Qingyuan $\mathrm{Xu}$, Zhiguang Shan, Chaojiang Ma. A review of research on digital economy measurement index systems at home and abroad. Survey the World, vol. 000(011), pp. 52-58, 2018.

8. Xiaobing Wang, Chunpeng Kang, Chunyan Dong. Re-understanding of 'Internet +' modern agriculture. Issues in Agricultural Economics, 2018.

9. Song Jiang, Yuxin Sun. An empirical study on the effect of digital economy on the real economy. Scientific Research Management. Vol. 41(05), pp. 32-39, 2020.

10. Hongcun Gao. Seize the opportunity of the digital economy and promote the high-quality development of the agricultural industry. Rural Work Newsletter. Vol. 59, 2018.

11. Hui Li. Research on the deep integration of digital economy and agriculture and rural development in Hebi City. Food Science and Technology and Economy. vol. 44(06), pp. 119-122, 2019.

12. Runhong Shan. Digital copyright identification technology based on digital fingerprint. Electronic Science and Technology. vol. 25(09), pp. 124-125, 2012. 